\title{
Optimization and field experiment of an adjustable device for sugar beet digger
}

\author{
Fangyan Wang \\ (College of Mechanical and Electrical Engineering, Qingdao Agricultural University, Qingdao 266041, China)
}

\begin{abstract}
The harvesting operation, which affects the energy consumption and application performance, usually determines the harvesting effect and production quality of the crop. An adjustable sugar beet excavation device was designed to put the excavation equipment into practice by reducing harvest loss. The device is composed of an excavation disc, hub, pedestal, threaded rod, adjustable nut, boom, mounting seat, leak proof disc, etc. Through theoretical analysis, it was found that the excavation disc and the adjustment mechanism, which determine the excavation space and loading condition of the device, are important to the excavation device. Key parameters of the excavation disc were selected according to the growth status of sugar beet and the requirements of excavation space, with $340 \mathrm{~mm}$ as the radius of the excavation disc and $7.5^{\circ}$ as the edge angle $\theta$. The adjustment mechanism parameters were selected to change the operating parameters (inclination angle $\beta$ and deflection angle $\gamma$ ) easily. Through the theoretical and experimental preliminary research, the key components structure and parameters of the excavation device were determined. By Central Composite Design (CCD) method, the regression equation was established, with rotation angle $\alpha$, opening angle $\varepsilon$ and excavation depth $\mathrm{h}$ as factors, and break rate, loss rate and excavation resistance as performance indexes. The influence of factors on performance indexes was estimated. The optimized parameter combination is: $35.37^{\circ}$ of rotation angle, $15.08^{\circ}$ of opening angle and $135.20 \mathrm{~mm}$ of the excavation depth. Experiments verified that the adjustable excavation device worked stably and achieved smooth excavation without congestion. The test indexes improved, with $0.6 \%$ of break rate, $1.1 \%$ of loss rate and $2312.8 \mathrm{~N}$ of the excavation resistance. This satisfied the requirement for beet harvest quality, and is roughly consistent with the optimization result. The research results can provide reference for the research on mechanized harvesting technology and equipment of sugar beet.
\end{abstract}

Keywords: sugar beet, excavation, harvest, parameter optimization DOI: $10.25165 /$ j.ijabe.20211406.6667

Citation: Wang F Y. Optimization and field experiment of an adjustable device for sugar beet digger. Int J Agric \& Biol Eng, 2021; 14(6): 68-74.

\section{Introduction}

Due to the influence of the modes of beet planting, soil conditions and differences in beet size, beet roots are difficult to be harvested, thus a highly adaptable and quality-reliable device was required for digging ${ }^{[1,2]}$. In foreign countries, because beets are mainly planted in a standardized manner, the size of roots is uniform, and the level of harvest mechanization is high, which is represented by the German rotary digging devices and shovel digging devices. Domestic research on the device for beet harvest is still in the preliminary stage, and there is a lack of highly adaptable technology and devices for digging and harvesting with mature performance, meanwhile, the research on the self-propelled beet combined harvester is rare ${ }^{[3,4]}$. Existing beet harvest devices have different structures, with obvious differences in the adaptation to the environment and performance characteristics, and the fixed working parameters limit the application scope of digging devices to a certain extent ${ }^{[5,6]}$. At present, the fork-type digging structure studied by the Nanjing Institute of Agricultural Mechanization of the Ministry of Agriculture and Rural Affairs has improved the digging performance and self-cleaning property, and reduced the amount of beet clay ${ }^{[7]}$, but it will also cause great damage to beet

Received date: 2021-04-09 Accepted date: 2021-10-15

Biographies: Fangyan Wang, Assistant Professor, research interests: agricultural mechanization engineering. College of Mechanical and Electrical Engineering, Qingdao Agricultural University, Qingdao 266041, China. Tel: +86-15806426016, Email: wfy_66@163.com. roots. The ploughshare-type digging device manufactured by Changzhou Hansen Machinery Co., Ltd. possesses high working efficiency, but it is not suitable for the beet harvest environment with high soil hardness, and beet roots are easily broken. The radial disk digging device developed by Qingdao Agricultural University has the advantages of low digging resistance and good digging performance, but the digging parameters are fixed, making it only suitable for the harvest conditions where the water content in soil and beet size are moderate Currently ${ }^{[8-10]}$, there is no beet digging device whose digging parameters can be flexibly adjusted according to the working condition, so as to meet the harvest conditions where the beet size and soil condition are significantly different ${ }^{[11,12]}$.

Therefore, in this study, a beet digging device with flexibly adjustable digging working parameters was designed to realize the smooth digging and low-loss harvest of beets ${ }^{[13,14]}$. The device has a unique adjustment mechanism and positioning method, which provides theoretical and technical reference for the R\&D of similar devices for beet harvest.

\section{Structure and principle}

\subsection{Overall structure}

The adjustable digging device mainly consists of a digging disc, shaft hub, shaft brackets, threaded rod, semi-circular adjusting block, boom, conical block, mounting base, and an anti-leak disc, among which the shaft brackets, the threaded rod, and the semi-circular adjustment block constitute the adjustment mechanism of opening angle, and the threaded rod, the conical 
block and the nut constitute the adjustment mechanism of rotation angle. The structure is shown in Figure 1. The rotation angle of the digging device can be changed by adjusting the connection position of the threaded rod and changing the distance between the mounting base and the boom. By using the pin hinge relationship between the boom and the shaft bracket, and the adjustment mechanism of opening angle, the distance between the two shaft brackets can be changed, and the dihedral angle between the two digging discs is adjusted, that is, the opening angle of the digging device. In order to ensure the adjustment range of the opening angle, the position of the contact of boom with the threaded rod is an oval hole groove, and the relative position is limited by two semicircular adjustment blocks connected by bolts. The inner hole of one semicircular adjustment block is a light hole, and the other adjustment block is fitted with screw through internal thread. The forward motion of two shaft brackets is realized by turning the threaded rod and using the motion of the two anti-wire semicircular blocks. The digging disc and the anti-leak disc are installed on the shaft hub by bolts, and the shaft hub and the shaft bracket are connected through bearings.

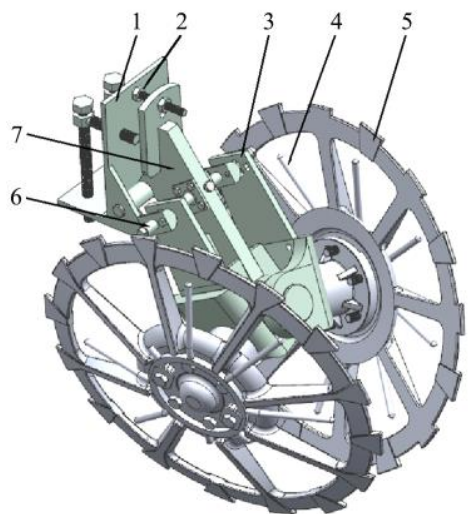

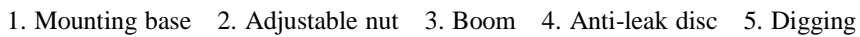
disc 6. Semicircular adjustment block 7. Shaft bracket

Figure 1 Structure of digging device

\subsection{Working principle}

Under the traction of a tractor, the digging discs of the device enter the soil and roll around the axle on the shaft bracket with the support of its friction with the soil. Because the two digging discs are arranged in space, a spatial digging squeeze channel is formed which is wide at the front and narrow at the back, which can cut, loosen and lift the soil containing beets. Adjust the included angle between the digging plates through the stern shaft bracket to change the angle of the digging plates; The angle between the digging disk and the ground can be adjusted through the adjustable nut, and the appropriate angle can be adjusted according to different ground conditions, so as to improve the digging effect of sugar beet. In this process, part of the loose soil leaks from both sides of the digging discs, and the remaining soil and beets are lifted and separated with the rolling of the digging discs, thus the entire digging process is completed. It can be seen that the structure of the digging device and the space passage of digging have a great impact on the looseness and flow state of soil, and the load and movement of beets, which is the key to the design of the digging device.

\section{Key components and the determination of parameters}

\subsection{Digging disc}

The digging disc is the core component of the digging device.
Its outer contour is a partial spherical surface, and the outer blade extends into a conical surface to improve the ability of the digging shovel to enter and break soil. The structure and parameters of the digging disc are shown in Figure 2.

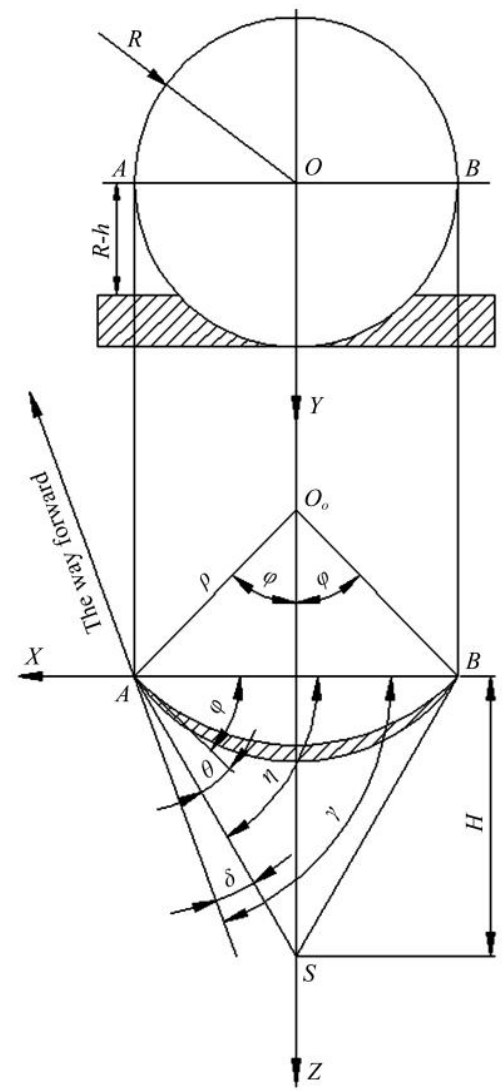

Figure 2 Digging disc structure

According to the geometric relationship,

$$
\begin{gathered}
R=\rho \sin \varphi \\
\eta=\varphi+\theta \\
\gamma=\eta+\delta \\
\tan \eta=\frac{H}{R} \\
H=\sqrt{\rho^{2}-R^{2}}
\end{gathered}
$$

where, $\delta$ is the clearance angle, $\left({ }^{\circ}\right) ; \eta$ is the cutting edge surface angle $\left({ }^{\circ}\right) ; \theta$ as the cutting edge angle, $\left(^{\circ}\right) ; \varphi$ is the half angle of sphere center, $\left(^{\circ}\right) ; \rho$ is the radius of curvature of digging disc, mm; $R$ is the radius of the digging disc, $\left({ }^{\circ}\right) ; \gamma$ is deflection angle, $\left({ }^{\circ}\right) ; H$ is the cone height of conical surface of digging disk blade, $\mathrm{mm}$; and the influence of the inclination angle is ignored.

In the coordinate system, the equation of the conical surface of the outer blade of the digging shovel satisfies

$$
x^{2}+y^{2}=\left(\frac{R z}{H}\right)^{2}
$$

The intersection of the horizontal surface section which is $h$ from the bottom of the trench with the conical surface of the outer blade of the digging shovel is a hyperbola. Set the deflection angle, clearance angle, angle of cutting edge surface and radius of the digging disc as $\gamma_{0}, \delta_{0}, \eta_{0}$ and $R_{0}$ respectively, and the following formula is satisfied

$$
\tan \eta_{0}=\tan \left(\gamma_{0}-\delta_{0}\right)=\frac{H R_{0}}{R^{2}}=\tan \eta \frac{R_{0}}{R}
$$

It can be seen that the angle of the cutting edge surface varies on different horizontal sections of the digging disc, and gradually 
increases as the horizontal section approaches the center of the rotation of the digging disc. At the same time, the clearance angle $\delta_{0}$ and deflection angle $\gamma_{0}$ have influence on the digging performance and the digging resistance of the digging disc. The working relationship of the deflection angle is shown in Figure 3.

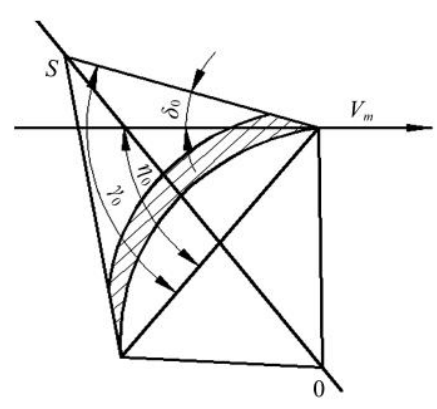

a. $\gamma_{0}>\eta_{0}$

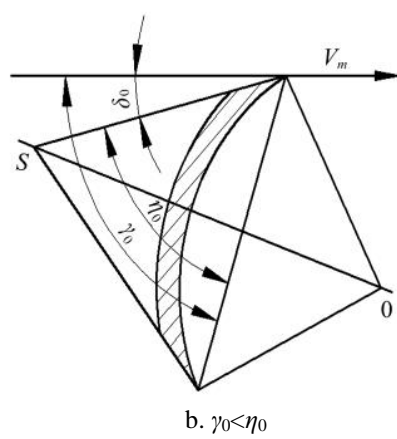

b. $\gamma_{0}<\eta_{0}$
Figure 3 Positional relationship

When the deflection angle $\gamma_{0}$ is extremely small, the clearance angle of the digging disc $\delta_{0}$ is less than 0 , and the conical surface of the digging disc squeezes the uncultivated soil, leading to an increase in traction resistance, which is not conducive for the digging disc to enter the soil. When the deflection angle $\gamma_{0}$ is large enough, the clearance angle $\delta_{0}$ is greater than 0 , and the conical surface of the digging shovel does not scrape the uncultivated soil. Therefore, when the clearance angle $\delta_{0} \geq 0$, only the cutting edge of the conical surface of the digging shovel contacts the soil, then

$$
\gamma_{0}=\eta_{0}=\arctan \left(\frac{H R_{0}}{R^{2}}\right)
$$

That is,

$$
\tan \gamma_{0}=2 \sqrt{\left(\frac{\rho}{R}\right)^{2}-1} \sqrt{h^{2}-\left(\frac{h}{2 R}\right)^{2}}
$$

where, $h$ is the digging depth of digging disc, $\mathrm{mm}$;

According to the planting agronomy and harvest conditions of beets, under a certain working depth, the larger the radius $R$ of the digging disc, the better the passing ability of digging, and the higher the digging rate of beets. However, limited by the row spacing of beet planting, the radius of the digging shovel cannot be too large, usually $300-375 \mathrm{~mm}^{[15-17]}$, thus the radius $R$ of the digging disc is $340 \mathrm{~mm}$. Generally, the smaller the included angle between the cutting edge surface of the digging disc and the side of the beet, the smaller the side pressure on the beet and the less the damage to it. The angle of cutting edge $\theta$ should not only meet the requirements of the strength of cutting edge, but also should be as small as possible to reduce the cutting resistance. Based on the requirements for the strength of cutting edge of the digging disc, the angle of cutting edge $\theta$ is determined to be $7.50^{\circ}$. At the same time, the curvature radius of the digging disc $\rho$ affects the loosening of soil and the soil-turning performance, but the change in the curvature radius of the digging disc has little impact on the breaking effect of the soil and the movement trajectory of beets ${ }^{[18]}$. Generally, the digging depth of beet is less than $150 \mathrm{~mm}$, and by combining Equations (1), (2), (3), and (9), the curvature radius $\rho$ is preliminarily determined to be $1040 \mathrm{~mm}$ to avoid the contact between the conical back of the digging shovel and the trench wall, so as to improve the effect of the digging mechanism and working stability.

\subsection{Adjustment mechanism}

The inclination angle $\beta$ and deflection angle $\gamma$ of the digging device are important performance parameters, which affect the effect of cutting, breaking and turning of soil. In terms of the structural characteristics of the digging device, it is more convenient to adjust the inclination $\beta$ and deflection angle $\gamma$ by changing the opening angle $\varepsilon$ and rotation angle $\alpha$ of the digging device, and the following equations are satisfied

$$
\begin{aligned}
& \tan \beta=\tan \varepsilon \cdot \cos \alpha \\
& \tan \gamma=\tan \varepsilon \cdot \sin \alpha
\end{aligned}
$$

When the opening angle $\varepsilon$ is constant, increasing the rotation angle $\alpha$ decreases the inclination angle $\beta$ and increases the deflection angle $\gamma$, and the orientation ability and the digging performance of the digging device are promoted, while the soil transportation is reduced and the digging resistance is improved; when the rotation angle $\alpha$ is constant, increasing the opening angle $\varepsilon$ will increase the inclination angle $\beta$ and deflection angle $\gamma$, and the orientation ability and transportation performance of the digging device will be enhanced, while the digging performance is reduced, and the digging resistance will be increased. In order to ensure the smooth adjustment of the working parameters, the adjustment mechanism of the opening angle and the rotation angle is shown in Figure 4.

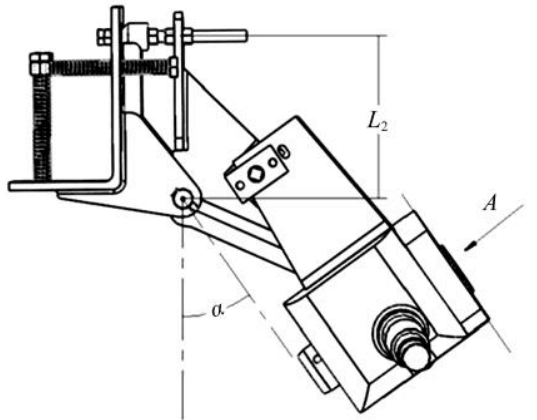

a. Main view

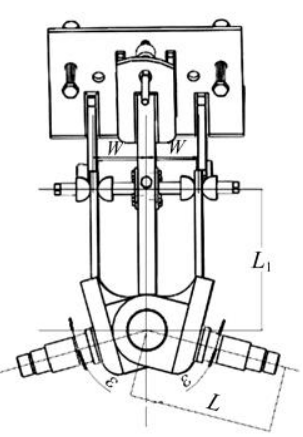

b. A view
Figure 4 Adjustment mechanism

It can be known from the working principle that the adjustment amount of opening angle $\Delta \varepsilon$ and that of the rotation angle $\Delta \alpha$ satisfy

$$
\begin{gathered}
\tan \Delta \varepsilon=\frac{L_{1} n_{1} p_{1}}{L_{1}^{2}+W^{2}+W n_{1} p_{1}} \\
\tan \Delta \alpha=\frac{n_{2} p_{2}}{L_{2}}
\end{gathered}
$$

where, $p_{1}$ and $p_{2}$ represent the pitch of the threaded rod, mm; $L_{1}$ and $L_{2}$ denote the length of the turning radius, $\mathrm{mm} ; n_{1}$ and $n_{2}$ are the number of revolutions of the threaded rod; $W$ is the spacing between shaft brackets, $\mathrm{mm} ; \varepsilon_{0}$ and $i_{0}$ denote the initial values of the opening angle and the rotation angle, $\left({ }^{\circ}\right) ; \Delta \varepsilon$ is the adjustment amount of opening angle $\varepsilon,\left(^{\circ}\right) ; \Delta \alpha$ is the adjustment amount of the rotation angle $\alpha,\left(^{\circ}\right)$.

Thus the opening angle $\varepsilon$ and rotation angle i of the digging device are

$$
\begin{aligned}
\varepsilon & =\varepsilon_{0} \pm \Delta \varepsilon \\
& =\varepsilon_{0} \pm \arctan \frac{L_{1} n_{1} p_{1}}{L_{1}^{2}+W^{2}+W n_{1} p_{1}} \\
\alpha & =\alpha_{0} \mu \Delta \alpha=\alpha_{0} \mu \arctan \frac{n_{2} p_{2}}{L_{2}}
\end{aligned}
$$

where, $\varepsilon_{0}$ and $\alpha_{0}$ denote the initial values of the opening angle and the rotation angle, $\left({ }^{\circ}\right)$.

Generally, the spacing between each row of beets is $500 \mathrm{~mm}$ or $650 \mathrm{~mm}$, and the diameter of beet is $60-120 \mathrm{~mm}^{[12]}$. Combining the structural characteristics and test results of the above-mentioned radial disc digging device with fixed parameters, rotating shaft 
length $L$ is determined to be $240 \mathrm{~mm}$, the adjustment range of the opening angle $\varepsilon<18^{\circ}$ and the adjustment range of the rotation angle $\alpha<50^{\circ}$.

Based on the adjustment space and requirements for installation position of the mechanism, the distance between the shaft brackets $\mathrm{W}$ is determined to be $90 \mathrm{~mm}, L_{1}$ to be $155 \mathrm{~mm}$, and $L_{2}$ to be $200 \mathrm{~mm}$ to meet the needs of parameter adjustment during the harvest process.

\section{Materials and method}

\subsection{Test conditions and methods}

In October 2018, the test of beet harvest was conducted in Yi'an County, Qiqihar, Harbin. The experimental field is loam, with the soil hardness of $85.3 \mathrm{kPa}$, the water content of $11.2 \%$, the spacing between rows of beets is $650 \mathrm{~mm}$, the spacing between beets is $180 \mathrm{~mm}$, and the height of ridge is $150 \mathrm{~mm}$.

The working performance of the digging device was tested using the beet combined harvester. The steel wire rope was used to connect the tension sensor with two 65-horsepower tractors, and the sensor tension of the harvester under no load and digging status was recorded by the collection system of the tension sensor, and the working resistance of the digging device was calculated ${ }^{[19,20]}$. According to the Method for Test of Beet Harvester (JB/ T6276-2007) and The Operation Quality of Beet Harvester (NY/T 1412-2018), the indicators of the beet harvest data were measured. Design-Expert 8 statistical software was adopted to analyze the test results, and the optimal results and combination of parameters were determined $^{[21-27]}$. The working status is shown in Figure 5.

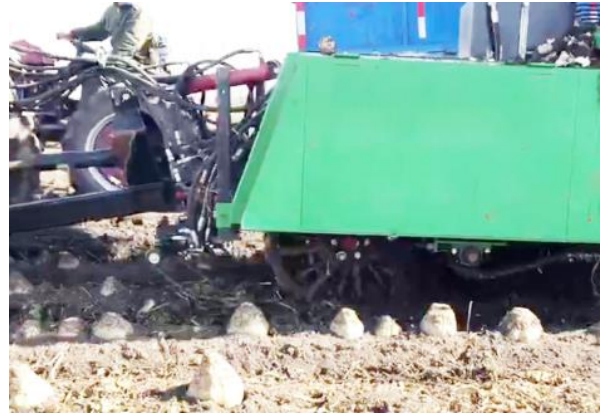

Figure 5 Working status

\subsection{Test programs and dates}

The performance test was conducted using the rotation angle $x_{1}$, opening angle $x_{2}$ and the digging depth $x_{3}$ of the digging device as factors, and the important evaluation indicators (break rate $\gamma_{1}$, loss rate $\gamma_{2}$ ) of the quality of beet harvest and the energy consumption indicator (digging resistance $\gamma_{3}$ ) were used as evaluation indicators. On the basis of ensuring smooth harvest of beets, by combining the single factor test of the digging device, the parameter range of the smooth digging of beet was determined: the range of the rotation angle is $30^{\circ}-40^{\circ}$, the range of opening angle is $13.5^{\circ}-16.5^{\circ}$, and the range of digging depth is $100-160 \mathrm{~mm}$. In order to determine the optimal combination of parameters, design of Central Composite Design (CCD) test schemes was used. The test factors and levels are shown in Table 1, and the test programs and results are displayed in Table 2 .

Table 1 Test factors and levels

\begin{tabular}{ccccc}
\hline \multirow{2}{*}{ Factor } & Coding & \multicolumn{3}{c}{ Test level } \\
\cline { 3 - 5 } & & -1 & 0 & 1 \\
\hline$\alpha / \mathrm{mm}$ & $x_{1}$ & 30 & 35 & 40 \\
$\varepsilon / \mathrm{mm}$ & $x_{2}$ & 13.5 & 15.0 & 16.5 \\
$h / \mathrm{mm}$ & $x_{3}$ & 100 & 130 & 160 \\
\hline
\end{tabular}

Table 2 Programmes and dates

\begin{tabular}{|c|c|c|c|c|c|c|}
\hline No. & $x_{1}(\alpha)$ & $x_{2}(\varepsilon)$ & $x_{3}(h)$ & $y_{1}\left(\gamma_{1}\right)$ & $y_{2}\left(\gamma_{2}\right)$ & $y_{3}\left(\gamma_{3}\right)$ \\
\hline 1 & 30 & 13.5 & 100 & 2.4 & 3.0 & 0.32 \\
\hline 2 & 40 & 13.5 & 100 & 4.1 & 4.8 & 0.46 \\
\hline 3 & 30 & 16.5 & 100 & 6.8 & 0.0 & 0.45 \\
\hline 4 & 40 & 16.5 & 100 & 8.2 & 0.0 & 0.33 \\
\hline 5 & 30 & 13.5 & 160 & 0.0 & 4.5 & 0.39 \\
\hline 6 & 40 & 13.5 & 160 & 0.0 & 1.0 & 0.50 \\
\hline 7 & 30 & 16.5 & 160 & 0.0 & 0.0 & 0.54 \\
\hline 8 & 40 & 16.5 & 160 & 0.0 & 0.0 & 0.37 \\
\hline 9 & 26.59 & 15 & 130 & 0.0 & 0.0 & 0.48 \\
\hline 10 & 43.40 & 15 & 130 & 0.0 & 0.0 & 0.46 \\
\hline 11 & 35 & 12.48 & 130 & 0.0 & 9.6 & 0.37 \\
\hline 12 & 35 & 17.52 & 130 & 0.0 & 0.9 & 0.38 \\
\hline 13 & 35 & 15 & 79.55 & 12.2 & 0.0 & 0.34 \\
\hline 14 & 35 & 15 & 180.45 & 0.0 & 0.0 & 0.44 \\
\hline 15 & 35 & 15 & 130 & 1.2 & 0.0 & 0.26 \\
\hline 16 & 35 & 15 & 130 & 0.0 & 0.0 & 0.24 \\
\hline 17 & 35 & 15 & 130 & 0.0 & 0.0 & 0.26 \\
\hline 18 & 35 & 15 & 130 & 0.0 & 0.8 & 0.25 \\
\hline 19 & 35 & 15 & 130 & 0.9 & 0.0 & 0.26 \\
\hline 20 & 35 & 15 & 130 & 1.6 & 1.2 & 0.27 \\
\hline
\end{tabular}

\section{Results and discussion}

The dimensionless regression equations of each factor with the break rate $y_{1}$, loss rate $y_{2}$ and digging resistance $y_{3}$ were obtained by response surface analysis ${ }^{[28-30]}$.

$$
\begin{aligned}
& y_{1}=0.60+0.24 x_{1}+0.64 x_{2}-3.06 x_{3}-0.062 x_{1} x_{2}- \\
& 0.41 x_{1} x_{3}-1.09 x_{2} x_{3}-0.1 x_{1}^{2}-0.1 x_{2}^{2}+2.05 x_{3}^{2} \\
& y_{2}=0.34-0.12 x_{1}-2.05 x_{2}-0.17 x_{3}+0.21 x_{1} x_{2}- \\
& 0.66 x_{1} x_{3}+0.29 x_{2} x_{3}-0.15 x_{1}^{2}+1.70 x_{2}^{2}-0.15 x_{3}^{2} \\
& y_{3}=0.26-0.005392 x_{1}+0.002696 x_{2}+0.03 x_{3}-0.067 x_{1} x_{2}- \\
& 0.01 x_{1} x_{3}+0.0025 x_{2} x_{3}+0.075 x_{1}^{2}+0.042 x_{2}^{2}+0.047 x_{3}^{2}
\end{aligned}
$$

By using the dimension reduction method, one factor is set to the level of 0 to study the impact of the other two factors on the test indicators, and the response surface was drawn, as shown in Figure 6. The analysis of variance is shown in Table 3, and the fitting degree of the regression models of the evaluation indicators is extremely significant $(p<0.01)$. The lack of fit of each regression model is not significant, indicating that the regression models fit the actual test well.

It can be found from Figure 6a that the digging depth has a great impact on the break rate which decreases with the increase in the digging depth. The effect of the interaction between the digging depth and the rotation angle on break rate is not significant; the interaction between the rotation angle and opening angle has no obvious effect on break rate which increases with the rise in the rotation angle and the opening angle respectively; the break rate gradually improves with the increase of the opening angle, and the effect of the interaction between the digging depth and the opening angle on the break rate is significant. When the digging depth is larger than $130 \mathrm{~mm}$, the rotation angle is less than $36^{\circ}$, the opening angle is less than $15.3^{\circ}$, and the break rate of beet is low. It can be seen from Figure $6 \mathrm{~b}$ that the opening angle has a great impact on the loss rate, which decreases with the increasing opening angle. The effect of the interaction between the digging depth and the rotation angle on the loss rate is significant; the interaction between the rotation angle and opening angle has no remarkable influence 
on the loss rate which decreases with the increase of the rotation angle; the interaction of the digging depth and the opening angle on the loss rate is not prominent, and the loss rate decreases with the increase of the digging depth. When the digging depth is less than $118 \mathrm{~mm}$, the rotation angle is less than $32^{\circ}$, or the digging depth is larger than $142 \mathrm{~mm}$, the rotation angle is greater than $36^{\circ}$, the opening angle is greater than $15.3^{\circ}$, and the break rate of beet is low. It can be seen from Figure $8 \mathrm{c}$ that the digging depth and rotation angle have a great effect on the digging resistance which decreases first and then increases with the increasing digging depth and the rotation angle respectively; the effect of the interaction between the digging depth and the rotation angle on the digging resistance is significant; the interaction of rotation angle and opening angle has a remarkable effect on the digging resistance which decreases first and then increases with the increasing rotation angle and the opening angle respectively; the interaction of digging depth and opening angle on the digging resistance is not significant, but the digging resistance first decreases and then increases with the increase of the digging depth and the opening angle respectively. When the digging depth is $112-136 \mathrm{~mm}$, the rotation angle is $32^{\circ}-36^{\circ}$, the opening angle is $14.7^{\circ}-15.3^{\circ}$, and the digging resistance of beet is low. It can be seen that there is a difference in the influence of each parameter on the evaluation indicators. The selection of appropriate combination of parameters can improve the harvest performance of the digging device.
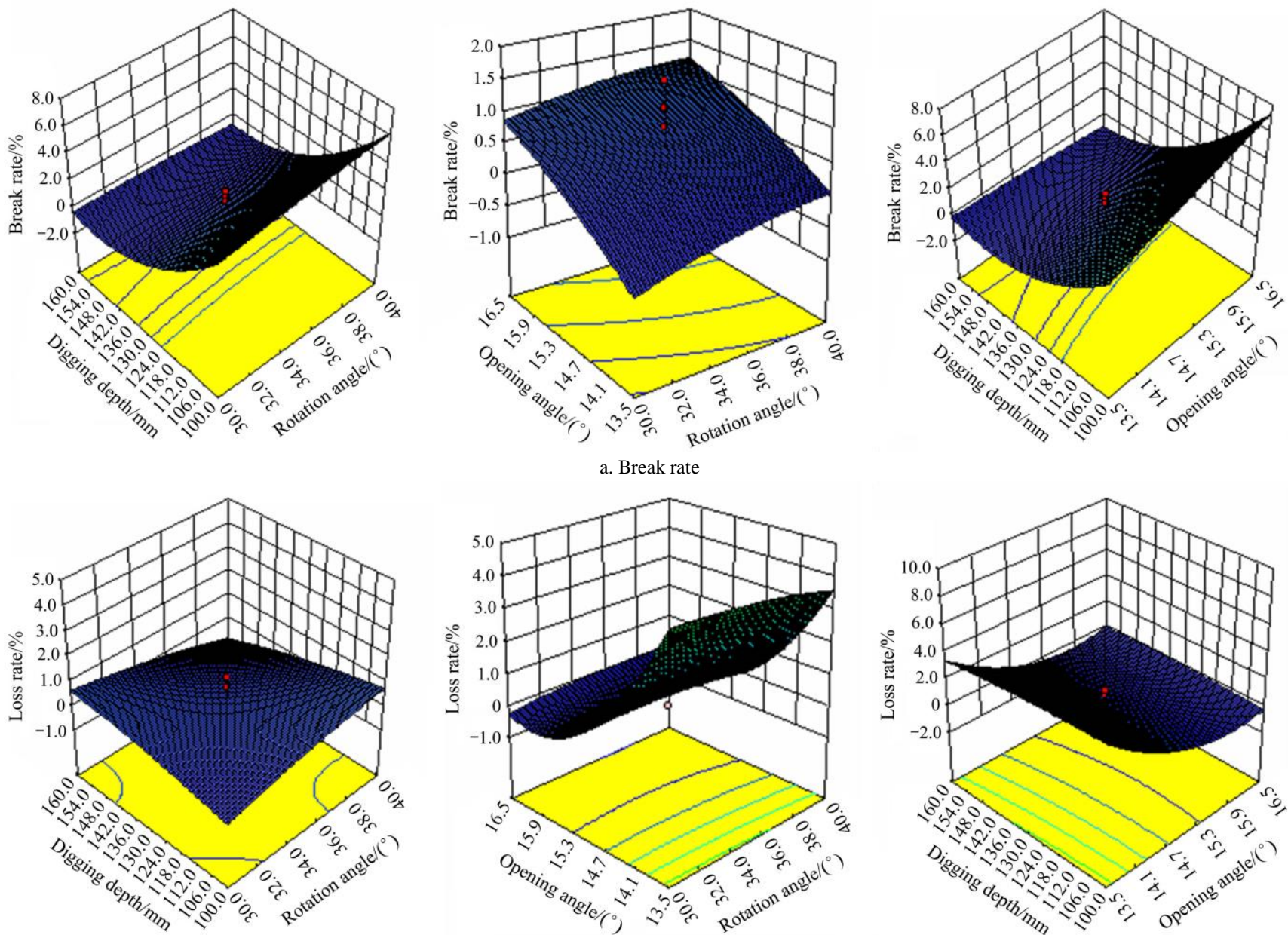

a. Break rate
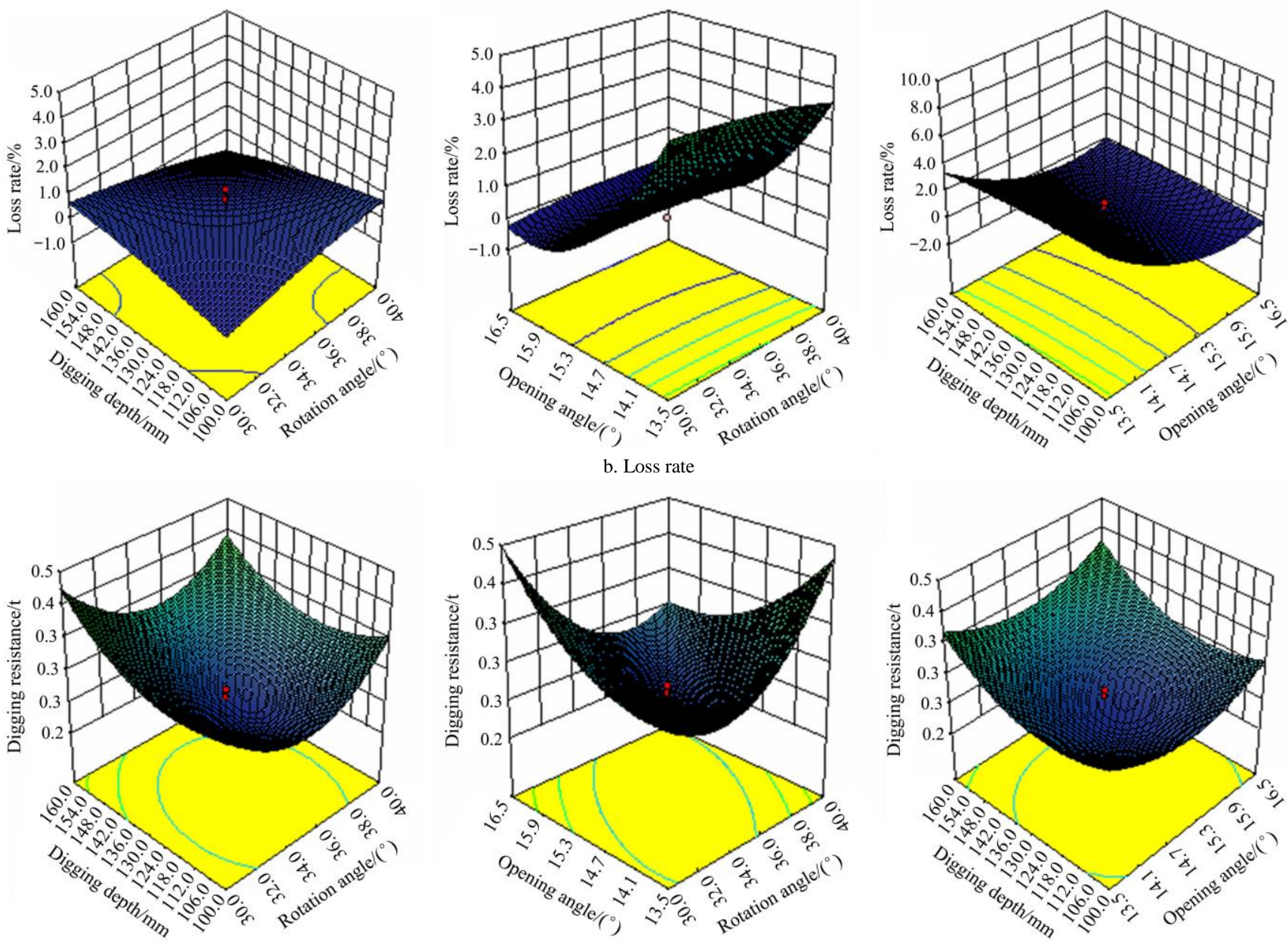

Figure 6 Effects of influence factors on different indicators 
Table 3 Analysis of variance

\begin{tabular}{|c|c|c|c|c|c|c|c|c|c|c|c|c|c|c|c|}
\hline \multirow{2}{*}{ Source } & \multicolumn{5}{|c|}{ Break rate } & \multicolumn{5}{|c|}{ Loss rate } & \multicolumn{5}{|c|}{ Excavation resistance } \\
\hline & $\begin{array}{l}\text { Sum of } \\
\text { squares }\end{array}$ & Freedom & $\begin{array}{l}\text { Mean } \\
\text { square }\end{array}$ & $\begin{array}{c}F \\
\text { value }\end{array}$ & $\begin{array}{c}p \\
\text { value }\end{array}$ & $\begin{array}{l}\text { Sum of } \\
\text { squares }\end{array}$ & Freedom & $\begin{array}{l}\text { Mean } \\
\text { square }\end{array}$ & $\begin{array}{c}F \\
\text { value }\end{array}$ & $\begin{array}{c}p \\
\text { value }\end{array}$ & $\begin{array}{l}\text { Sum of } \\
\text { squares }\end{array}$ & Freedom & $\begin{array}{l}\text { Mean } \\
\text { Square }\end{array}$ & $\begin{array}{c}F \\
\text { value }\end{array}$ & $\begin{array}{c}p \\
\text { value }\end{array}$ \\
\hline Model & 208.52 & 9 & 23.17 & 20.93 & $* *$ & 106.78 & 9 & 11.86 & 14.34 & $* *$ & 0.17 & 9 & 0.02 & 315.63 & $* *$ \\
\hline A-A & 0.80 & 1 & 0.80 & 0.72 & & 0.21 & 1 & 0.21 & 0.26 & & 0.00 & 1 & 0.00 & 6.72 & $*$ \\
\hline B-B & 5.54 & 1 & 5.54 & 5.01 & $*$ & 57.13 & 1 & 57.13 & 69.05 & $* *$ & 0.00 & 1 & 0.00 & 1.68 & \\
\hline $\mathrm{AB}$ & 0.03 & 1 & 0.03 & 0.03 & & 0.36 & 1 & 0.36 & 0.44 & & 0.04 & 1 & 0.04 & 616.82 & $* *$ \\
\hline $\mathrm{AC}$ & 1.36 & 1 & 1.36 & 1.23 & & 3.51 & 1 & 3.51 & 4.24 & $*$ & 0.00 & 1 & 0.00 & 13.54 & $* *$ \\
\hline $\mathrm{BC}$ & 9.46 & 1 & 9.46 & 8.55 & $*$ & 0.66 & 1 & 0.66 & 0.80 & & 0.00 & 1 & 0.00 & 0.85 & \\
\hline$A^{2}$ & 0.15 & 1 & 0.15 & 0.14 & & 0.34 & 1 & 0.34 & 0.42 & & 0.08 & 1 & 0.08 & 1379.09 & $* *$ \\
\hline $\mathrm{B}^{2}$ & 0.15 & 1 & 0.15 & 0.14 & & 41.73 & 1 & 41.73 & 50.44 & $* *$ & 0.02 & 1 & 0.02 & 422.27 & $* *$ \\
\hline $\mathrm{C}^{2}$ & 60.76 & 1 & 60.76 & 54.89 & $* *$ & 0.34 & 1 & 0.34 & 0.42 & & 0.03 & 1 & 0.03 & 536.77 & $* *$ \\
\hline Lack of fit & 8.54 & 5 & 1.71 & 3.38 & & 6.86 & 5 & 1.37 & 4.85 & & 0.00 & 5 & 0.00 & 0.11 & \\
\hline Pure error & 2.53 & 5 & 0.51 & & & 1.41 & 5 & 0.28 & & & 0.00 & 5 & 0.00 & & \\
\hline Cor total & 219.59 & 19 & & & & 115.06 & 19 & & & & 0.17 & 19 & & & \\
\hline
\end{tabular}

Note: **highly significant $(p<0.01)$, *significant $(p<0.05)$. A is the rotation angle factor; $\mathrm{B}$ is the opening angle factor; $\mathrm{C}$ is the digging depth factor.

The factors such as rotation angle, opening angle and digging depth were optimized using the regression model with the minimum value of break rate, loss rate, and digging resistance as objective functions of performance. After optimization, optimal combination of parameters was obtained: the rotation angle is $35.37^{\circ}$, the opening angle is $15.08^{\circ}$, and the digging depth is $135.20 \mathrm{~mm}$. At this time, the break rate predicted by the model is 0 , the loss rate is 0 , and the digging resistance is $0.263 \mathrm{t}(2577.4 \mathrm{~N})$. Optimal combination of parameters: rotation angle is $35^{\circ}$, opening angle is $15^{\circ}$, and the digging depth is $135 \mathrm{~mm}$. Under this combination of parameters, the adjustable digging device has good performance, with the break rate of $0.6 \%$, the loss rate of $1.1 \%$, and the digging resistance of $2312.8 \mathrm{~N}$, which is similar to the predicted results, and meets the requirements of the quality of beet harvest. According to the beet growth and working conditions, appropriate combination of working parameters can be selected for the digging device to adjust the digging range and space, which is helpful for the smooth and low-loss digging of beets.

\section{Conclusions}

(1) An adjustable digging device was designed, and the inclination angle $\beta$, deflection angle $\gamma$, digging depth $\mathrm{h}$, and radius of digging disc $\mathrm{R}$ were determined as the main parameters affecting the working performance. Based on the geometric relationship between the parameters, the opening and rotation angles that are easy to be controlled were selected to adjust the deflection angle and inclination angle, so as to change the working parameters of the digging device.

(2) By adopting CCD test design schemes, with rotation angle, opening angle and digging depth as factors, the break rate and loss rate of beets, and the digging resistance as evaluation indicators, the regression equations of factors and indicators were obtained to determine the influence law of each factor, and determine the optimal combination of parameters: the rotation angle is $35^{\circ}$, opening angle is $15^{\circ}$, and the digging depth is $135 \mathrm{~mm}$.

(3) The test verified that the harvest performance indicators of the digging device meet the harvest requirements. The digging range and space can be adjusted according to the beet growth and working conditions, which is helpful to the digging of beet, and can provide a reference for the research on mechanized technology and equipment of beet harvest.

(4) After testing and verification, the harvest performance index of the digging device meets the harvesting requirements, the breaking rate is $0.6 \%$, the loss rate is $1.1 \%$, and the digging resistance is $2312.8 \mathrm{~N}$. The digging range and space can be adjusted according to the growth status and working conditions of sugar beet, which is helpful for the digging of sugar beet, and can provide reference for the research of mechanized sugar beet harvesting technology and equipment. The adaptability and stability of the adjustable excavating device are better than the performance of the existing spoke disc excavating device. Compared with the disc excavation device developed by Qingdao Agricultural University, the adaptability and performance are improved, the breaking rate is $62.5 \%$ lower, and the loss rate is $39.6 \%$ lower; compared with the fork excavator, the breaking rate is $81.4 \%$ lower. The loss rate is reduced by $68.9 \%$; compared with the vibration excavation device the breaking rate is lower by $90.6 \%$, and the loss rate is reduced by $76.7 \%$.

\section{Acknowledgements}

We acknowledge that this work was financially sponsored by National Natural Science Foundation of China (51505246, 51775290), the National Key Research and Development Program of China (2016YFD0701200).

\section{[References]}

[1] Wang F Y. Research on harvesting process and digging location for sugar beet. Chinese Journal of Agricultural Mechanization, 2016; 37(4): 27-30. (in Chinese)

[2] Wang F Y, Zhang D X. Experimental analysis on physical characteristics of sugar beet. Transactions of the CSAE, 2012; 28(S2): 297-303. (in Chinese)

[3] Wang F Y, Zhang D X. The experimental research on the influence factors of sugar beet pulling force. Journal of Agricultural Mechanization Research, 2015; 37(10): 173-176. (in Chinese)

[4] Wang F Y, Zhang D X. The experimental research on mechanical properties of sugar beet. Journal of Agricultural Mechanization Research, 2015; 37(9): 206-210. (in Chinese)

[5] Fan S X, Hou S, Zhao Y. Overview of full mechanization of sugar beet production in domestic and overseas. Journal of Agricultural Mechanization Research, 2011; 33(3): 12-15. (in Chinese)

[6] Wang S Y, Hu Z C, Zhang H J, Wu H C, Peng B L, Gu F W. Sugar 
beet production and mechanization harvest analysis in domestic and overseas. Chinese Journal of Agricultural Mechanization, 2013; 34(3): 20-25. (in Chinese)

[7] Wang F Y. Research on harvesting process and digging location for sugar beet. Chinese Journal of Agricultural Mechanization, 2016; 37(4): 27-30. (in Chinese)

[8] Wang F Y. Experiment on optimization structure and parameters with guide detection mechanism. Journal of Agricultural Mechanization Research, 2015; 37(11): 212-215. (in Chinese)

[9] Wang F Y. Simulation research on conveyor cleaning device for sugar beet based on ADAMS. Chinese Journal of Agricultural Mechanization, 2016; 37(2): 57-61. (in Chinese)

[10] Wang F Y, Zhang D X. Design and experiment of disc-dig sugar beet combine. Transactions of the CSAE, 2014; 29(13): 7-14. (in Chinese)

[11] Grimmo, Grimmo self-propelled beet harvester REXOR Platinum Edition. Agricultural Machinery, 2019; 3: 128.

[12] Zhao S, Wang J S, Wang F Y, Zhang F F, Li X. Research status and prospect of agricultural soil vibratory-cutting technology. Journal of Agricultural Mechanization Research, 2017; 39(7): 244-251. (in Chinese)

[13] Wang, F. The study on structure of radial disk digging device with finite element analysis. Agricultural Mechanization Research, 2018; 40(2): 66-69, 84. (in Chinese)

[14] Gu F W, Hu Z C, Wu H C, Peng B L, Gao X M, Wang S Y. Development and experiment of 4LT-A staggered-dig sugar beer combine. Transactions of the CSAE, 2014; 30(23): 1-9. (in Chinese)

[15] Wang F Y, Zhang D X. Parameter optimization of sugar beet digging device with disc type. Transactions of the CSAE, 2015; 31(11): 17-23. (in Chinese)

[16] Wang F Y, Zhang D X. Design and experiment of disc-dig sugar beet combine. Transactions of the CSAE, 2013; 29(13): 7-14. (in Chinese)

[17] Liao Y T, Zheng J, Liao Q X, Ding Y C, Gao L P. Design and experiment of positive and negative pressure combined tube-needle centralized seeding device for American ginseng. Transactions of the CSAM, 2019; 50(3): 46-57. (in Chinese)

[18] Moreno F, Cabrera F, Fernandez-Boy E, Giron I F, Fernandez J E, Bellido B. Irrigation with saline water in the reclaimed marsh soils of south-west Spain: Impact on soil properties and cotton and cotton and sugar beet crops. Agricultural Water Management, 2001; 48: 133-150.

[19] Katerji N, van Hoorn J W, Hamdy A, Mastrorilli M. Salinity effect on crop development and yield, analysis of salt tolerance according to several classification methods. Agricultural Water Management, 2003; 62: 37-66.

[20] Bulgakov V, Adamchuk V, Nozdrovický L, Ihnatiev Y. Theory of vibrations of sugar beet leaf harvester front-mounted on universal tractor. Acta Technologica Agriculturae, 2017; 20(4): 96-103.

[21] Wang F Y. Design and experimental of key mechanisms for sugar beet combine with disc-dig type. China Agricultural University, 2014. (in Chinese)

[22] Lv J Q, Yu J Y, Feng X, Li Z H, Li J C, Liu Z Y. Design and experiment of roller potato grading machine. Transactions of the CSAM, 2019; 50(2): 323-332. (in Chinese)

[23] Gu F W, Hu Z C, Wu H C, Peng B L, Gao X M, Wang S Y. Development and experiment of 4LT-A staggered-dig sugar beer Combine. Transactions of the CSAE, 2014; 30(23): 1-9. (in Chinese)

[24] Wang F Y, Zhang D X. Parameter optimization and test on auto guide device for disc type sugar beet harvester. Transactions of the CSAE, 2015 31(8): 27-33. (in Chinese)

[25] Wang C, Liu C J, Li H W, Wang Q J, He J, Lu C Y. Design and experiment of asymmetric large-small double discs ditching device. Transactions of the CSAE, 2018; 34(18): 28-36. (in Chinese)

[26] Yu C C, Xu L M, Wang Q J, Yuan Q C, Ma S, Niu C. Design and experiment of bilateral operation intra-row auto obstacle avoidance weeder for trellis cultivated grape. Transactions of the CSAE, 2019; 35(5): 1-9. (in Chinese)

[27] Oliver Mark. Grimme shows off $653 \mathrm{hp} \mathrm{Rexor} \mathrm{Platinum} \mathrm{beet} \mathrm{harvester}$ Farmers Weekly, 2019; 170(22). https://www.fwi.co.uk/machinery/ root-crop-equipment/root-crop-harvesters/grimme-shows-off-new-653hp-re xor-platinum-beet-harvester.

[28] Huang J C, Shen C, Ji A M, Tian K P, Zhang B, Li X W, et al. Design and test of two-wheeled walking hemp harvester. Int J Agric \& Biol Eng, 2020; 13(1): 127-137.

[29] Zheng K, McHugh A D, Li H W, Wang Q J, Lu C Y, Hu H N, et al. Design and experiment of anti-vibrating and anti-wrapping rotary components for subsoiler cum rotary tiller. Int J Agric \& Biol Eng, 2019; 12(4): 47-55.

[30] Huang J C, Tian K P, Shen C, Zhang B, Liu H L, Chen Q M, et al. Design and parameters optimization for cutting-conveying mechanism of ramie combine harvester. Int J Agric \& Biol Eng, 2020; 13(6): 94-103. 